Original article

\title{
Who is dying from COVID-19 and when? An Analysis of fatalities in Tamil Nadu, India
}

\author{
Edwin Sam Asirvatham ${ }^{a}$, Charishma Jones Sarman ${ }^{\mathrm{b}}$, Sakthivel P. Saravanamurthy ${ }^{\mathrm{c}}$, \\ Periasamy Mahalingam ${ }^{\mathrm{d}}$, Swarna Maduraipandian ${ }^{\mathrm{e}}$, Jeyaseelan Lakshmanan ${ }^{\mathrm{f}, *}$ \\ ${ }^{\text {a }}$ Technical Adviser (Health Systems \& Policy), Health Systems Research India Initiative, (HSRII), Thiruvananthapuram, Kerala, 695004, India \\ ${ }^{\mathrm{b}}$ Independent Public Health Consultant, New Delhi, India \\ c Independent Public Health Research Consultant, New Delhi, India \\ ${ }^{\mathrm{d}}$ Consultant Physician, New Hope Medical Centre, Chennai, India \\ ${ }^{\mathrm{e}}$ Consultant Physician, Shepherd Hospital, Chennai, India \\ ${ }^{\mathrm{f}}$ Professor, Department of Biostatistics, Christian Medical College, Vellore, Tamil Nadu, 632 002, India
}

\section{A R T I C L E I N F O}

\section{Keywords:}

COVID-19 in India

Age and sex-specific death rate

Comorbidities of COVID-19

Time interval between infection and death

\begin{abstract}
A B S T R A C T
Background: As the number of COVID-19 cases continues to rise, public health efforts must focus on preventing avoidable fatalities. Understanding the demographic and clinical characteristics of deceased COVID-19 patients; and estimation of time-interval between symptom onset, hospital admission and death could inform public health interventions focusing on preventing mortality due to COVID-19.

Methods: We obtained COVID-19 death summaries from the official dashboard of the Government of Tamil Nadu, between 10th May and July 10, 2020. Of the 1783 deaths, we included 1761 cases for analysis.

Results: The mean age of the deceased was 62.5 years (SD: 13.7). The crude death rate was 2.44 per 100,000 population; the age-specific death rate was 22.72 among above 75 years and 0.02 among less than 14 years, and it was higher among men (3.5 vs 1.4 per 100,000 population). Around 85\% reported having any one or more comorbidities; Diabetes (62\%), hypertension (49.2\%) and CAD (17.5\%) were the commonly reported comorbidities. The median time interval between symptom onset and hospital admission was 4 days (IQR: 2, 7); admission and death was 4 days (IQR: 2,7 ) with a significant difference between the type of admitting hospital. One-fourth of $(24.2 \%)$ deaths occurred within a day of hospital admission.

Conclusion: Elderly, male, people living in densely populated areas and people with underlying comorbidities die disproportionately due to COVID-19. While shorter time-interval between symptom onset and admission is essential, the relatively short time interval between admission and death is a concern and the possible reasons must be evaluated and addressed to reduce avoidable mortality.
\end{abstract}

\section{Background}

As of July 10, 2020, the SARS-CoV-2 has infected around 820,000 individuals with 22,000 deaths in India. ${ }^{1}$ Tamil Nadu, a south Indian state with a population of around 72 million, ${ }^{2}$ reported around 130,000 cases and 1829 deaths which was $16 \%$ of total confirmed cases and $8.3 \%$ of total deaths in India. ${ }^{3}$ The rapid spread of the disease has undoubtedly become a burden to health systems in several countries, as a significant proportion of elderly, immunosuppressed and those with underlying metabolic, cardiovascular or respiratory diseases continue to develop severe forms of COVID-19 and are at an increased risk for adverse outcomes. ${ }^{4}$ At the same time, evidence is emerging to caution that young and adult general population are also at considerable risk for critical illness and adverse outcome. ${ }^{5}$

As the number of cases continues to increase, public health efforts must focus on preventing avoidable fatalities. When a health system is burdened beyond its capacity and the morale of health care workers is affected, the standard of care would be compromised, leading to negative health outcomes. Current therapeutic strategies to deal with COVID19 are only supportive, and prevention efforts aimed at reducing

\footnotetext{
* Corresponding author. Department of Biostatistics, Christian Medical College, Vellore, Tamil Nadu, 632002 , India.

E-mail addresses: aedwinsam@yahoo.com (E.S. Asirvatham), charishma.jones@gmail.com (C.J. Sarman), pssaravanamurthy@gmail.com (S.P.Saravanamurthy), pmahan76@hotmail.com (P. Mahalingam), drmswarna@gmail.com (S. Maduraipandian), ljey@hotmail.com, prof.ljey@gmail.com (J. Lakshmanan).
} 
transmission in the community are considered as the most effective methods. ${ }^{6}$ However, fatality due to COVID-19 could be reduced, if there is early and accurate diagnosis, identification of clinical features of severe risks, prediction of disease progression and appropriate clinical intervention. Further, early seeking of medical care by people with exposure and symptoms, especially the most vulnerable, could substantially reduce the spread of infection, severity and fatality due to this disease and produce better clinical outcome. ${ }^{7}$

Currently, COVID-19 has its presence across the globe, generating new information, fresh knowledge and evidence continuously. However, there are still many unknowns and ambiguity about the demographic and clinical characteristics of deceased COVID-19 patients; the different time intervals between the time of infection and outcome - death or recovery. ${ }^{8}$ The currently available literature indicates varying information across regions and countries, emphasizing the need for generating evidence for a specific geography, population, and context.

This study aims to understand the demographic and clinical characteristics of deceased COVID-19 patients; and estimate the timeinterval between symptom onset, hospital admission and death, which could inform public health interventions focusing on preventing mortality due to COVID-19.

\section{Methods}

We obtained COVID-19 death summaries from the official dashboard of the Government of Tamil Nadu (https://stopcorona.tn.gov.in/), a South Indian state. Each death summary consisted of information such as district, age, gender, type of admitting hospital, presence of comorbidities, presenting symptoms, number of days with symptoms, date of hospital admission and date of death. We collected information from May 10, 2020 to July 10, 2020.

A total of 1783 deaths were reported during the period. We excluded 22 brought dead cases and finalised 1761 cases of deaths for analysis. For the analysis of comorbidities, we included only the cases that reported the presence or absence with details of comorbidities. For the analysis of presenting symptoms, we included only the death summaries that indicated the presence of symptoms with details, as the absence of symptoms on admission is not provided in death summaries. For the estimation of time intervals between symptom onset and hospital admission; admission and death, we excluded the cases referred from other hospitals due to the potential influence on the time intervals; and cases who did not have all the information.

We summarised the categorical variables as frequency and percentages; and continuous variables as mean, standard deviation (SD), median, and interquartile range (IQR) as appropriate. We analysed the continuous variables using independent t-test or Mann-Whitney test/ Kruskal-Wallis $\mathrm{H}$ test. The proportions for categorical variables were analysed using Chi-squared test $(\chi 2)$ test. The analyses were performed using SPSS version 24.0 (IBM Corp. Armonk, NY, USA).

\section{Results}

\subsection{Socio-demographic characteristics and age, sex-specific mortality}

Table 1 summarizes the details of deaths that were reported during the period of analysis. The mean age of the deceased was 62.5 years (SD: 13.7 years) without a significant difference between male (62.8 years; SD: 13.6) and female (61.8 years; SD: 14.2). The majority of the deceased were male (71.4\%). Chennai district, which is the state capital reported around $67 \%$ of all deaths reported in the state. Around $71 \%$ (1246) of deaths were recorded in public hospitals and the remaining $29 \%$ (515) occurred in private hospitals.

The crude death rate was 2.44 per 100,000 population (95\% CI: 2.43 , 2.45 ); the age-specific death rate was found to be highest (22.72 per 100,000; 95\% CI: 22.48, 22.97) among population aged above 75 years and lowest among children aged less than 14 years $(0.02$ deaths per
Table 1

Age, gender, hospital and geographic specific death rate (n-1761).

\begin{tabular}{|c|c|c|c|c|c|}
\hline & Description & $\begin{array}{l}\text { No of } \\
\text { deaths } \\
(\%)\end{array}$ & $\begin{array}{l}\text { Death per } \\
100,000 \\
\text { people }\end{array}$ & $\begin{array}{l}95 \% \\
\text { Conf. } \\
\text { Interval }\end{array}$ & P Value \\
\hline \multirow[t]{6}{*}{ Age } & Up to 14 & $4(0.2)$ & 0.02 & $\begin{array}{l}0.02 \\
0.03\end{array}$ & \multirow[t]{6}{*}{$<0.001$} \\
\hline & 14 to 29 & $26(1.5)$ & 0.13 & $\begin{array}{l}0.13 \\
0.14\end{array}$ & \\
\hline & 30 to 44 & $\begin{array}{l}161 \\
(9.1)\end{array}$ & 0.96 & $\begin{array}{l}0.95 \\
0.98\end{array}$ & \\
\hline & 45 to 59 & $\begin{array}{l}457 \\
(26.0)\end{array}$ & 3.97 & $\begin{array}{l}3.93 \\
4.00\end{array}$ & \\
\hline & 60 to 74 & $\begin{array}{l}783 \\
(44.5)\end{array}$ & 12.93 & $\begin{array}{l}12.84, \\
13.02\end{array}$ & \\
\hline & $\begin{array}{l}75 \text { and } \\
\text { above }\end{array}$ & $\begin{array}{l}330 \\
(18.7)\end{array}$ & 22.72 & $\begin{array}{l}22.48 \\
22.97\end{array}$ & \\
\hline \multirow[t]{2}{*}{ Gender } & Male & $\begin{array}{l}1258 \\
(71.4)\end{array}$ & 3.48 & $\begin{array}{l}3.46 \\
3.50\end{array}$ & \multirow[t]{4}{*}{$<0.001$} \\
\hline & Female & $\begin{array}{l}503 \\
(28.6)\end{array}$ & 1.40 & $\begin{array}{l}1.38 \\
1.41\end{array}$ & \\
\hline \multirow[t]{2}{*}{$\begin{array}{l}\text { Admitting } \\
\text { Hospital }\end{array}$} & Public & $\begin{array}{l}1246 \\
(70.8)\end{array}$ & - & - & \\
\hline & Private & $\begin{array}{l}515 \\
(29.2)\end{array}$ & - & - & \\
\hline \multirow[t]{3}{*}{ Geography } & $\begin{array}{l}\text { Chennai } \\
\text { (Capital) }\end{array}$ & $\begin{array}{l}1182 \\
(67.1)\end{array}$ & 25.44 & $\begin{array}{l}25.29 \\
25.58\end{array}$ & \multirow[t]{3}{*}{$<0.001$} \\
\hline & $\begin{array}{l}\text { Other } \\
\text { districts }\end{array}$ & $\begin{array}{l}579 \\
(32.9)\end{array}$ & 0.86 & $\begin{array}{l}0.85 \\
0.86\end{array}$ & \\
\hline & Total & $\begin{array}{l}1761 \\
(100)\end{array}$ & 2.44 & $\begin{array}{l}2.43 \\
2.45\end{array}$ & \\
\hline
\end{tabular}

100,000 children; 95\% CI: 0.02, 0.03). The age-specific death rate increased as the age increased. The death rate was significantly higher among men (3.5 per 100,000 population; $95 \%$ CI: $3.46,3.50)$ compared to women (1.4 per 100,000 population; $95 \%$ CI: $1.38,1.41$ ). Chennai district recorded a significantly higher death rate of 25.44 per 100,000 (95\% CI: 25.29, 25.58), while all the other districts together recorded 0.86 deaths per 100,000 population ( $95 \%$ CI: $0.85,0.86)$.

\subsection{Pre-existing comorbidities in deceased COVID-19 patients}

Among the 1,678 cases that reported the presence or absence with details of comorbidities, $85.3 \%$ reported any one or more comorbidities at the time of hospital admission (Table-2). Diabetes was found to be the most common comorbidity associated with $62 \%$ of the deceased; hypertension and CAD were present among $49.2 \%$ and $17.5 \%$ of the deceased respectively. The coexistence of diabetes and hypertension; and coexistence of diabetes, hypertension and CAD were found in $36.6 \%$ and $8.7 \%$ of the individuals respectively.

As expected, the study found a significantly higher presence of comorbidities among the elderly compared to younger age groups ( $p<$ 0.001 ) in terms of the presence of any one or more comorbidities, diabetes, hypertension, chronic obstructive pulmonary disease (COPD), coronary artery disease (CAD), coexistence of diabetes and hypertension, and coexistence of diabetes, hypertension and CAD. As age increased, the presence of comorbidities seems to increase significantly. The presence of any one or more comorbidities $(p=0.002)$ and comorbidities categorised as others $(p<0.001)$ were found to be higher among women. Private hospitals reported to have treated a significantly higher proportion of deceased patients with comorbidities such as diabetes $(\mathrm{p}=0.01)$, hypertension $(\mathrm{p}<0.001), \operatorname{CAD}(\mathrm{p}<0.06)$, asthma $(\mathrm{p}<$ $0.06)$, the coexistence of diabetes and hypertension $(\mathrm{p}<0.001)$, and the coexistence of diabetes, hypertension and CAD $(\mathrm{p}=0.007)$, whereas public hospitals reported to have treated higher proportion of patients with CKD ( $\mathrm{p}<0.001)$. Around $18 \%$ of deceased reported having other comorbidities such as hypothyroidism, dementia, encephalopathy, cerebrovascular diseases (CVS), hepatitis etc., however, the presence of these as independent comorbidity was found to be very low $(3.6 \%, 61)$. 
Table 2

Age, gender and hospital specific comorbidities.

\begin{tabular}{|c|c|c|c|c|c|c|c|c|c|c|c|c|}
\hline \multirow{2}{*}{$\begin{array}{c}\text { Presence of } \\
\text { comorbidities }\end{array}$} & \multicolumn{3}{|c|}{ Gender } & \multicolumn{5}{|c|}{ Age Groups (in years) } & \multicolumn{3}{|c|}{ Admitting hospital } & \multirow{2}{*}{$\begin{array}{c}\text { Total } \\
(\mathrm{n}-1678)\end{array}$} \\
\hline & $\begin{array}{c}\text { Male (n - } \\
1194) \\
\%(n)\end{array}$ & $\begin{array}{c}\text { Female (n - } \\
484) \\
\%(\mathrm{n})\end{array}$ & P Value & $\begin{array}{c}<45 \\
(\mathrm{n}- \\
189) \\
\%(\mathrm{n})\end{array}$ & $\begin{array}{c}45 \text { to } 59 \\
\text { (n - } \\
454) \\
\%(n)\end{array}$ & $\begin{array}{l}60 \text { to } 74 \\
\text { (n - } \\
735) \\
\%(n)\end{array}$ & $\begin{array}{l}>75 \\
(\mathrm{n}- \\
300) \\
\%(\mathrm{n})\end{array}$ & P Value & $\begin{array}{l}\text { Private(n - } \\
\text { 493) }\end{array}$ & $\begin{array}{l}\text { Public(n - } \\
\text { 1185) }\end{array}$ & P Value & \\
\hline $\begin{array}{l}\text { Any one } \\
\text { Comorbidity or } \\
\text { more }\end{array}$ & 83.6 (998) & $89.5(433)$ & 0.002 & $\begin{array}{c}64.0 \\
(121)\end{array}$ & $\begin{array}{c}81.3 \\
(369)\end{array}$ & $\begin{array}{c}89.9 \\
(661)\end{array}$ & $\begin{array}{c}93.3 \\
(280)\end{array}$ & $<0.001$ & $87.6(432)$ & 84.3 (999) & 0.080 & $\begin{array}{c}85.3 \\
(1431)\end{array}$ \\
\hline Diabetes & $61.3(732)$ & $63.2(306)$ & 0.464 & $\begin{array}{l}32.8 \\
(62)\end{array}$ & $\begin{array}{c}61.0 \\
(277)\end{array}$ & $\begin{array}{c}67.9 \\
(499)\end{array}$ & $\begin{array}{c}66.7 \\
(200)\end{array}$ & $<0.001$ & $66.3(327)$ & $60(711)$ & 0.015 & $\begin{array}{c}61.9 \\
(1038)\end{array}$ \\
\hline Hypertension & $48.6(580)$ & $50.6(245)$ & 0.448 & $\begin{array}{l}16.9 \\
(32)\end{array}$ & $\begin{array}{c}42.7 \\
(194)\end{array}$ & $\begin{array}{c}55.4 \\
(407)\end{array}$ & $\begin{array}{c}64 \\
(192)\end{array}$ & $<0.001$ & $55.8(275)$ & $46.4(550)$ & $<0.001$ & $\begin{array}{c}49.2 \\
(825)\end{array}$ \\
\hline COPD & $2.8(34)$ & $2.1(10)$ & 0.364 & $0.5(1)$ & $1.1(5)$ & $2.7(20)$ & $6(18)$ & $<0.001$ & $2.0(10)$ & $2.9(34)$ & 0.326 & $2.6(44)$ \\
\hline $\mathrm{CAD}$ & $17.9(214)$ & $16.3(79)$ & 0.434 & $3.7(7)$ & $\begin{array}{l}13.7 \\
(62)\end{array}$ & $\begin{array}{c}20.3 \\
(149)\end{array}$ & $25(75)$ & $<0.001$ & 20.1 (99) & 16.4 (194) & 0.068 & $\begin{array}{l}17.5 \\
(293)\end{array}$ \\
\hline Any Cancer & $2.3(28)$ & 2.9 (14) & 0.515 & $2.6(5)$ & $2.4(11)$ & $2.4(18)$ & $2.7(8)$ & 0.995 & 3.7 (18) & $2.0(24)$ & 0.052 & $2.5(42)$ \\
\hline CKD & $11.4(136)$ & $9.5(46)$ & 0.260 & $\begin{array}{l}10.6 \\
(20)\end{array}$ & $\begin{array}{l}10.1 \\
(46)\end{array}$ & $\begin{array}{l}11.4 \\
(84)\end{array}$ & $\begin{array}{l}10.7 \\
(32)\end{array}$ & 0.914 & $6.9(34)$ & $12.5(148)$ & 0.001 & $\begin{array}{l}10.8 \\
(182)\end{array}$ \\
\hline TB & $1.3(15)$ & $0.4(2)$ & 0.118 & $1.6(3)$ & $0.9(4)$ & $0.7(5)$ & $1.7(5)$ & 0.425 & $0.4(2)$ & $1,3(15)$ & 0.109 & 1.0 (17) \\
\hline Asthma & $2.6(31)$ & $4.1(20)$ & 0.097 & $4.2(8)$ & $2.2(10)$ & 2.6 (19) & 4.7 (14) & 0.157 & $4.3(21)$ & $2.5(30)$ & 0.060 & $3.0(51)$ \\
\hline DM \& HTN & 35.8 (427) & $38.6(187)$ & 0.268 & $7.9(15)$ & $\begin{array}{c}31.1 \\
(141)\end{array}$ & $\begin{array}{c}43.0 \\
(316)\end{array}$ & $\begin{array}{l}47.3 \\
(142)\end{array}$ & $<0.001$ & $43.0(212)$ & $33.9(402)$ & $<0.001$ & $\begin{array}{c}36.6 \\
(614)\end{array}$ \\
\hline DM \& HTN \& CAD & $8.9(106)$ & $8.3(40)$ & 0.686 & $0.5(1)$ & $5.5(25)$ & $\begin{array}{l}11.0 \\
(81)\end{array}$ & 13 (39) & $<0.001$ & $11.6(57)$ & 7.5 (89) & 0.007 & $8.7(146)$ \\
\hline Others & 14.5 (173) & $25.6(124)$ & $<0.001$ & $\begin{array}{l}23.3 \\
(44)\end{array}$ & $\begin{array}{l}14.1 \\
(64)\end{array}$ & $\begin{array}{c}17.4 \\
(128)\end{array}$ & $\begin{array}{l}20.3 \\
(61)\end{array}$ & 0.023 & $19.5(96)$ & $17.0(201)$ & 0.220 & $\begin{array}{c}17.7 \\
(297)\end{array}$ \\
\hline
\end{tabular}

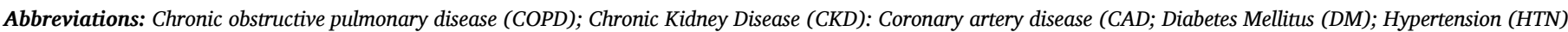

\subsection{Presenting symptoms on hospital admission}

Around 583 deaths summaries consisted of the details of presenting symptoms on admission (Table-3). Fever was the most common presenting symptom $(78.7 \%)$ reported by $80.5 \%$ of the deceased men and $73.7 \%$ of women. Breathing difficulty was reported by $75.8 \%$ of the patients (76.1\% of men, $75 \%$ of women); around $53 \%$ had cough $(54.8 \%$ of men and $49.3 \%$ of women) and $35.8 \%$ had fever, cough and breathing difficulty together (37.4\% of men and $31.6 \%$ of the women), however, the differences are not statistically significant. Diarrhoea and generalised weakness/myalgia were reported by $6.2 \%$, and $7.5 \%$ of the patients respectively, with women reporting significantly higher than men ( $\mathrm{p}=$ $0.01 ; p=0.02$ ). Fever was reported to be significantly higher among the older population $(\mathrm{p}=0.001)$.
3.4. Time intervals between symptom onset and hospital admission; admission and death

The median time interval between onset of symptoms and hospital admission was 4 days (IQR: 2, 7) without significant difference among gender and age groups (Table-4). The patients who were admitted in private hospitals had a median of 4 days of symptoms as compared to public hospital patients with 3 days of symptoms on admission $(\mathrm{P}<$ 0.005).

The median time interval between hospital admission and death was 4 days (IQR: 2, 7) and there are no significant differences among gender and age groups. However, it was significantly higher, 6 days (IQR: 2, 10) in private hospitals compared to 3 days (IQR: 1,6 ) in public hospitals ( $\mathrm{p}$ $<0.001)$. Around one fourth $(24.2 \%)$ of the reported deaths occurred within a day of hospital admission (public $27.8 \%$; private $15.3 \%$ ), $23.7 \%$ between 2 and 3 days (public 26.6\%; private 16.7\%), 8.1\% between 4 and 5 days (public $8.5 \%$; private $7.2 \%$ ) and $43.4 \%$ occurred after 5 days of admission (public $36.5 \%$; private $60.2 \%$ ) ( $<<0.001$ ).

Table 3

Age, gender and hospital specific presenting symptoms

\begin{tabular}{|c|c|c|c|c|c|c|c|c|c|c|c|c|}
\hline \multirow[t]{2}{*}{ Presenting symptoms } & \multicolumn{2}{|c|}{ Gender } & \multirow[b]{2}{*}{$\begin{array}{c}\mathrm{P} \\
\text { value }\end{array}$} & \multicolumn{4}{|c|}{ Age Groups in years } & \multirow[b]{2}{*}{$\begin{array}{c}\mathrm{P} \\
\text { value }\end{array}$} & \multicolumn{3}{|c|}{ Admitting hospital } & \multirow{2}{*}{$\begin{array}{c}\text { Total } \\
(\mathrm{n}- \\
583)\end{array}$} \\
\hline & $\begin{array}{c}\text { Male (n - } \\
431) \\
\%(n)\end{array}$ & $\begin{array}{c}\text { Female (n - } \\
152) \\
\%(\mathrm{n})\end{array}$ & & $\begin{array}{c}<45 \\
(n-34) \\
\%(n)\end{array}$ & $\begin{array}{c}45 \text { to } 59 \\
\text { (n - } \\
153) \\
\%(n)\end{array}$ & $\begin{array}{c}60 \text { to } 74(\mathrm{n}- \\
257) \\
\%(\mathrm{n})\end{array}$ & $\begin{array}{l}>75 \\
(\mathrm{n}- \\
139) \\
\%(\mathrm{n})\end{array}$ & & $\begin{array}{l}\text { Private(n - } \\
\text { 495) }\end{array}$ & $\begin{array}{l}\text { Public } \\
\text { (n - 88) }\end{array}$ & $\begin{array}{c}\mathrm{P} \\
\text { Value }\end{array}$ & \\
\hline Fever & $\begin{array}{c}80.5 \\
(347)\end{array}$ & 73.7 (112) & 0.077 & $\begin{array}{l}61.8 \\
(21)\end{array}$ & $\begin{array}{c}86.9 \\
(133)\end{array}$ & $80.2(206)$ & $\begin{array}{l}71.2 \\
(99)\end{array}$ & 0.001 & 79.8 (395) & $\begin{array}{l}72.7 \\
(64)\end{array}$ & 0.135 & $\begin{array}{l}78.7 \\
(459)\end{array}$ \\
\hline Breathing Difficulty & $\begin{array}{c}76.1 \\
(328)\end{array}$ & $75.0(114)$ & 0.785 & $\begin{array}{l}79.4 \\
(27)\end{array}$ & $\begin{array}{c}80.4 \\
(123)\end{array}$ & 75.9 (195) & $\begin{array}{l}69.8 \\
(96)\end{array}$ & 0.191 & $77.0(381)$ & $\begin{array}{l}69.3 \\
(61)\end{array}$ & 0.122 & $\begin{array}{c}75.8 \\
(442)\end{array}$ \\
\hline Cough & $\begin{array}{c}54.8 \\
(236)\end{array}$ & $49.3(75)$ & 0.250 & $\begin{array}{l}47.1 \\
(16)\end{array}$ & $\begin{array}{l}58.8 \\
(90)\end{array}$ & $51.8(133)$ & $\begin{array}{l}51.8 \\
(72)\end{array}$ & 0.427 & $53.7(266)$ & $\begin{array}{l}51.1 \\
(45)\end{array}$ & 0.652 & $\begin{array}{l}53.3 \\
(311)\end{array}$ \\
\hline Diarrhoea & $4.6(20)$ & $10.5(16)$ & 0.010 & $5.9(2)$ & $5.2(8)$ & $5.1(13)$ & $\begin{array}{c}9.4 \\
(13)\end{array}$ & 0.359 & $6.1(30)$ & $6.8(6)$ & 0.786 & $6.2(36)$ \\
\hline $\begin{array}{l}\text { General weakness/ } \\
\text { Myalgia }\end{array}$ & $6.0(26)$ & $11.8(18)$ & 0.020 & $\begin{array}{c}14.7 \\
(5)\end{array}$ & $3.9(6)$ & $8.6(22)$ & $\begin{array}{l}7.9 \\
(11)\end{array}$ & 0.123 & $8.3(41)$ & $3.4(3)$ & 0.111 & $7.5(44)$ \\
\hline $\begin{array}{l}\text { Fever, Breathing } \\
\text { difficulty and cough }\end{array}$ & $\begin{array}{c}37.4 \\
(161)\end{array}$ & $31.6(48)$ & 0.202 & $\begin{array}{l}35.3 \\
(12)\end{array}$ & $\begin{array}{l}42.5 \\
(65)\end{array}$ & $34.2(88)$ & $\begin{array}{l}31.7 \\
(44)\end{array}$ & 0.232 & $36.6(181)$ & $\begin{array}{l}31.8 \\
(28)\end{array}$ & 0.392 & $\begin{array}{l}35.8 \\
(209)\end{array}$ \\
\hline Others & $7.9(34)$ & $7.9(12)$ & 0.998 & $5.9(2)$ & $6.5(10)$ & $6.6(17)$ & $\begin{array}{l}12.2 \\
(17)\end{array}$ & 0.191 & 7.9 (39) & $8.0(7)$ & 0.981 & $7.9(46)$ \\
\hline
\end{tabular}


Table 4

Age, gender and hospital specific time intervals.

\begin{tabular}{|c|c|c|c|c|c|c|c|c|c|c|c|c|c|}
\hline \multirow[t]{2}{*}{ Description } & & \multirow[b]{2}{*}{$\mathrm{N}$} & \multirow[b]{2}{*}{ Mean } & \multicolumn{4}{|c|}{$\begin{array}{l}\text { Time interval between symptoms onset and } \\
\text { hospital admission (n-512) }\end{array}$} & \multicolumn{6}{|c|}{ Time interval between admission and death $(1,710)$} \\
\hline & & & & Median & SD & IQR & $P$ value & $\mathrm{N}$ & Mean & Median & SD & IQR & $P$ value \\
\hline \multirow[t]{4}{*}{ Age } & $<45$ years & 31 & 4.1 & 3.0 & 2.5 & $2-6$ & 0.098 & 186.0 & 5.4 & 4.0 & 5.4 & $1-7$ & 0.19 \\
\hline & $45-59$ years & 131 & 5.1 & 4.0 & 3.1 & $2-7$ & & 445.0 & 5.2 & 4.0 & 4.7 & $2-8$ & \\
\hline & $60-74$ years & 224 & 4.6 & 4.0 & 3.0 & $2-6$ & & 761.0 & 5.0 & 3.0 & 4.9 & $2-7$ & \\
\hline & 75 years and above & 126 & 4.3 & 3.0 & 3.1 & $2-5$ & & 318.0 & 5.2 & 4.0 & 4.7 & $2-8$ & \\
\hline \multirow[t]{2}{*}{ Gender } & Male & 375 & 4.7 & 4.0 & 3.1 & $2-7$ & 0.23 & 1220 & 5.2 & 4.0 & 4.8 & $2-7$ & 0.88 \\
\hline & Female & 137 & 4.2 & 4.0 & 2.8 & $2-5$ & & 490 & 5.2 & 4.0 & 4.9 & $2-8$ & \\
\hline \multirow[t]{3}{*}{ Admitting Hospital } & Public & 78 & 3.8 & 3.0 & 2.6 & $2-5$ & 0.005 & 1198 & 4.3 & 3.0 & 3.9 & $1-6$ & $<0.001$ \\
\hline & Private & 434 & 4.7 & 4.0 & 3.1 & $2-7$ & & 512 & 7.2 & 6.0 & 6.1 & $2-10$ & \\
\hline & Total & 512 & 4.6 & 4.0 & 3.0 & $2-7$ & & 1710 & 5.2 & 4.0 & 4.9 & $2-7$ & \\
\hline
\end{tabular}

\section{Discussion}

It is well documented that the COVID-19 pandemic takes different shapes and forms with varying mortality levels across geographic regions and countries. Though there are several studies from other countries that explained the characteristics of COVID-19 deaths, there is a dearth of peer-reviewed and published literature from India. Our study analysed the individual death summaries, and described the demographic and clinical characteristics of deceased COVID-19 patients; and estimated the time intervals between symptoms onset to hospital admission and death, which are critical for developing context and geographic-specific public health interventions focusing on reducing the mortality.

Our study findings indicated a disproportionate death rate among the categories of age, gender and geography. It is well demonstrated that age is the most significant risk factor for death due to COVID-19 and our study confirms the existing evidence. The increasing death rate with age is expected and it could be due to the higher prevalence of comorbidities, the reduced and less responsive innate and adaptive immune system among the elderly. ${ }^{9,10}$ The study reported a higher proportion of deaths $(71 \%)$ among men, though the proportion of total confirmed male cases was only $61 \%$ in the state ${ }^{11}$; and death per 100,000 male population was 3.4 as compared to 1.4 deaths per 100,000 female population. The less mortality among women has been reported in many studies which could be due to the protection of X chromosome and sex hormones, which play an important role in providing innate and adaptive immunity. ${ }^{12}$ The higher mortality among men could be due to the behavioral risk factors such as smoking, and alcohol consumption, which are relatively higher among men in India. ${ }^{13}$ Around $67 \%$ of deaths occurred in the capital district/city that recorded $58 \%$ of the total cases and just $6.4 \%$ of the population of the state. It is also the smallest and densest of all the districts in the state. ${ }^{2}$ The possible reasons could be lack of timely access to healthcare facilities, delayed seeking of care, overwhelming of health system with sudden surge of cases due to larger and exponential spread of the virus in the city.

The disease severity, increased admission rate in the intensive care units (ICU), and increased risk of mortality of COVID-19 are strongly associated with comorbidities such as diabetes, hypertension, obesity, cardiovascular disease, and respiratory system diseases and our study results confirm the previous findings. ${ }^{4,14,15}$ A study showed a hazard ratio of 2.59 among patients with two or more comorbidities compared to 1.79 among patients with one comorbidity. ${ }^{4}$ The Centers for Disease Control and Prevention reported 12 times higher deaths among patients with reported underlying conditions compared with those without reported underlying conditions (19.5\% versus $1.6 \%) .{ }^{16}$ In our study, the prevalence of any one or more comorbidities among the deceased was found to be around $85 \%$, and a significant proportion of deceased having other comorbidities such as diabetes, hypertension, and CAD respectively, with a strong association with age. Studies in China reported around $70 \%$ of deaths with any one comorbidity ${ }^{4,17}$, South Korea and Brazil reported $83 \%$ and $90.7 \%$; and these studies have reported hypertension, CAD, and diabetes as the main comorbidities among deaths. ${ }^{18,19}$

In our study, fever and breathing difficulty were each reported among 3/4th of the deceased, cough among half of them and around 1/ 3rd had fever, breathing difficulty and cough together, which are in line with the existing literature that fever, dry cough, shortness of breath and fatigue were the common symptoms on admission among the deceased patients $^{14,17}$ A meta-analysis of COVID-19 patients, showed fever (88.8\%) as the most common symptom, followed by dry cough (68\%) and fatigue. ${ }^{20}$ Another study that reviewed 24,410 cases across the world showed $78 \%$ of the cases with fever and $58 \%$ with cough. ${ }^{21}$ Though the study found an association between fever as a presenting symptom and age of the deceased, other symptoms and multiple concurrent symptoms did not indicate any association with age, gender and admitting hospital.

The median time interval between symptom onset and hospital admission was found to be 4 days, which is within the range mentioned in studies from China (4, 10 days), Singapore (4 days), Italy ( 7 days) that indicated a range of 3-10 days. ${ }^{14,22-24}$ The duration might change during the different phases of the epidemic due to rapid changes in the level of knowledge and awareness, stigma and discrimination, fear of the disease, programmatic interventions, health-seeking behavior, and access to health care services. As the epidemic progresses and there is continuous scale-up of public health and social interventions, the duration is expected to decrease, which could potentially limit the infection to others. According to our study, the median time interval between hospital admission and death was 4 days with a significant difference between patients admitted in private and public hospitals. Other countries reported a slightly higher, but a wide range of 5-16 days of time interval between hospital admission and death. ${ }^{14,25-27}$ A study that reviewed the length of stay across the world reported a shorter length of stay for those who died in hospital compared to those were discharged alive, with medians between 4 and 21 days compared to 4 and 53 days, respectively. ${ }^{28}$ The shorter period of hospital stay with negative outcome could be due to the delayed seeking of care due to economic reasons and lack of awareness about the disease, shortage of ICU facilities and ventilators, and overwhelming of hospitals that affect the capacity to deliver services effectively. The knowledge and awareness level of health workers, especially about the rapid progression to severe illness, treatment protocols, and the availability of effective drugs could also alter the duration of hospital stay. The relatively longer time interval between hospital admission and death in private hospitals, despite the higher proportion of deceased patients with comorbidities and presence of multiple concurrent symptoms could be due to the availability advanced technology and facilities to provide advanced life-supporting critical care, the affordability of those seeking health care and less burden of patients especially for COVID-19 management as compared to public hospitals.

Studies reported an average incubation period of 4-7 days, which is the time interval between the exposure/infection and onset of symptoms. ${ }^{4,22,29}$ Considering an average of 5 days between the 
exposure/infection and onset of symptoms, the estimated time interval between exposure/infection and death is 13 days in the state, whereas the time interval between symptom onset and death is just 8 days. Two studies have reported a higher average time interval of 17.8 and 18.5 days between the first recorded symptoms and death ${ }^{10,30}$, as compared to our study findings.

\section{Conclusion}

The study provides evidence from India, emphasizing that the elderly, male and people living in densely populated areas, and patients with underlying comorbidities die disproportionately due to COVID-19. The study estimated a time interval of 13 days between exposure to infection and death, with 4 days each for symptoms onset to hospital admission; and admission to death. None of the potential factors significantly alter the time interval between the onset of symptoms and hospital admission and death, except the type of treating hospital. The shorter time interval between the onset of symptoms and hospital admission would be critical as early diagnosis, supportive care and treatment could substantially reduce the mortality especially among the elderly and vulnerable population. However, the shorter time interval between admission and death is a concern and the possible reasons must be elucidated and addressed. Essentially, as the number of deaths from COVID-19 continues to increase, early diagnosis and timely treatment for moderate and severe cases are of crucial importance to reduce mortality.

\section{Limitations}

The analysis is based on data available in the public domain and it is limited to only deaths that were reported in the state through hospital admission. Hospital care can vary from general ward care to intensive care and we do not have disaggregated data for this. The data have limitations in terms of completeness such as, the presence of symptoms that were not reported in all the deaths.

\section{Funding}

This research did not receive any specific grant from funding agencies in the public, commercial, or not-for-profit sectors.

\section{Ethical approval}

Not required.

\section{Declaration of competing interest}

The authors declare that they have no conflict of interest.

\section{References}

1 GOI. COVID-19 Statewise Status as on 13th July 2020 New Delhi: Ministry of Health and Family Welfare, (MoHFW). Government of India; 2020. Available from https://www. mohfw.gov.in/.

2 CENSUS. Population. Enumeration Data (Final Population) New Delhi: Office of the Registrar General \& Census Commissioner. India; 2011. Available from: https://censu sindia.gov.in/2011census/population_enumeration.html.

3 GoT. COVID-19 Active Cases in Tamil Nadu Chennai. Health \& Family Welfare Department, Government of Tamil Nadu; 2020. Available from: https://nhmtn.maps. arcgis.com/apps/opsdashboard/index.html\#/095ad0a1c0254b058fa36b3 2d1ab1977.

4 Guan W-J, Liang W-H, Zhao Y, et al. Comorbidity and its impact on 1590 patients with COVID-19 in China: a nationwide analysis. Eur Respir J. 2020;55(5):2000547.

5 Adams SH, Park MJ, Schaub JP, Brindis CD, Irwin Jr CE. Medical vulnerability of young adults to severe COVID-19 illness - data from the national health interview survey. J Adolesc Health. 2020;67(3):362-368.

6 Napoli. MCMRACSCDRD. Evaluation and treatment coronavirus (COVID-19). In: StatPearls [Internet]. Treasure Island (FL): StatPearls Publishing; 2020.

7 Feng D, Jia N, Fang L-Q, et al. Duration of symptom onset to hospital admission and admission to discharge or death in SARS in mainland China: a descriptive study. Trop Med Int Health. 2009;14(s1):28-35.

8 Goh KJ, Choong MC, Cheong EH, et al. Rapid progression to acute respiratory distress syndrome: review of current understanding of critical illness from COVID-19 infection. Ann Acad Med Singapore. 2020;49(3):108-118.

9 Mueller AL, McNamara MS, Sinclair DA. Why does COVID-19 disproportionately affect older people? Aging (Albany NY). 2020;12(10):9959-9981.

10 Verity R, Okell LC, Dorigatti I, et al. Estimates of the severity of coronavirus disease 2019: a model-based analysis. Lancet Infect Dis. 2020;20(6):669-677.

11 GOI. Daily Report on Public Health Measures Taken for COVID-19 Chennai: Directorate of Public Health and Preventive Medicine. Health and Family Welfare Department, Government of Tamil Nadu; 2020. Available from: https://stopcorona.tn.gov.in wp-content/uploads/2020/03/Media-Bulletin-10-07-20-COVID-19-6-PM.pdf.

12 Li Y, Jerkic M, Slutsky AS, Zhang H. Molecular mechanisms of sex bias differences in COVID-19 mortality. Crit Care. 2020;24(1):405.

13 National IIPS. Family Health Survey-2017 (NFHS-4). New Delhi: Ministry of Heallth and Family Welfare,Government of India; 2017.

14 Chen T, Wu D, Chen H, et al. Clinical characteristics of 113 deceased patients with coronavirus disease 2019: retrospective study. BMJ. 2020;368:m1091.

15 Liu H, Chen S, Liu M, Nie H, Lu H. Comorbid chronic diseases are strongly correlated with disease severity among COVID-19 patients: a systematic review and metaanalysis. Aging Dis. 2020;11(3):668-678.

16 CDC. Severe. Outcomes among patients with coronavirus disease 2019 (COVID-19) United States, february 12-march 16, 2020. MMWR Morb Mortal Wkly Rep. 2020;69 (12):343-346.

17 Du Y, Tu L, Zhu P, et al. Clinical features of 85 fatal cases of COVID-19 from wuhan. A retrospective observational study. Am J Respir Crit Care Med. 2020;201(11): 1372-1379.

18 Pachiega J, Afonso AJdS, Sinhorin GT, et al. Chronic Heart Diseases as the Most Prevalent Comorbidities Among Deaths by COVID-19 in Brazil. Revista do Instituto de Medicina Tropical de São Paulo; 2020:62.

19 Korean Society of Infectious D, Korea Centers for Disease C, Prevention. Analysis on 54 mortality cases of coronavirus disease 2019 in the Republic of Korea from january 19 to march 10, 2020. J Kor Med Sci. 2020;35(12):e132-e.

20 Sanyaolu A, Okorie C, Marinkovic A, et al. Comorbidity and its impact on patients with COVID-19. SN Compr Clin Med. 2020:1-8.

21 Grant MC, Geoghegan L, Arbyn M, et al. The prevalence of symptoms in 24,410 adults infected by the novel coronavirus (SARS-CoV-2; COVID-19): a systematic review and meta-analysis of 148 studies from 9 countries. PloS One. 2020;15(6), e0234765.

22 Chen J, Qi T, Liu L, et al. Clinical progression of patients with COVID-19 in Shanghai, China. J Infect. 2020;80(5):e1-e6.

23 Pung R, Chiew CJ, Young BE, et al. Investigation of three clusters of COVID-19 in Singapore: implications for surveillance and response measures. Lancet. 2020;395 (10229):1039-1046.

24 Giacomelli A, Ridolfo AL, Milazzo L, et al. 30-day mortality in patients hospitalized with COVID-19 during the first wave of the Italian epidemic: a prospective cohor study. Pharmacol Res. 2020;158:104931.

25 Yang X, Yu Y, Xu J, et al. Clinical course and outcomes of critically ill patients with SARS-CoV-2 pneumonia in Wuhan, China: a single-centered, retrospective, observational study. Lancet Respir Med. 2020;8(5):475-481.

26 Lei S, Jiang F, Su W, et al. Clinical characteristics and outcomes of patients undergoing surgeries during the incubation period of COVID-19 infection. EClinicalMedicine. 2020:21.

27 Du R-H, Liang L-R, Yang C-Q, et al. Predictors of mortality for patients with COVID19 pneumonia caused by SARS-CoV-2: a prospective cohort study. Eur Respir J. 2020, 2000524.

28 Rees EM, Nightingale ES, Jafari Y, et al. COVID-19 length of hospital stay: a systematic review and data synthesis. medRxiv. 2020, 2020.04.30.20084780.

29 Lauer SA, Grantz KH, Bi Q, et al. The incubation period of coronavirus disease 2019 (COVID-19) from publicly reported confirmed cases: estimation and application. Ann Intern Med. 2020;172(9):577-582.

30 Zhou F, Yu T, Du R, et al. Clinical course and risk factors for mortality of adult inpatients with COVID-19 in Wuhan, China: a retrospective cohort study. Lancet. 2020;395(10229):1054-1062. 